\title{
Participatory Monitoring and Evaluation: Reviewing an Inclusive Approach in the South Africa's Government Wide Monitoring and Evaluation
}

Noluthando Matsiliza

\begin{abstract}
The premise of this paper is to canvass

for the inclusion of stakeholders in participating in the Government Wide Monitoring and Evaluation (GWM\&E) using the participatory monitoring and evaluation (PM\&E) approach. The focus is mainly on the practicality of using participatory methods as part of the agenda to cascade the implement the $M \& E$ into different stake-holders using various methods in South Africa. A variety of public participation methods should be recognised to benchmark for the inclusion of stakeholders at the local level in the evaluation and monitoring of public programmes and projects in order to allow

development policies and social accountability. Participation is increasingly recognised by countries as an integral part of $M \& E$ process while it offers environment for civic participation in a more inclusive and responsive approach towards service delivery and budget allocation in South Africa. Using a qualitative approach, conclusions and recommendations from this study contribute towards monitoring and evaluation of policies, programmes and projects in the field of Public Management. This study intends to address the paucity of literature on Participatory Monitoring and Evaluation in South Africa.
\end{abstract} more space for civil society engagement in

Keywords: Monitoring and Evaluation, Qualitative Approach, South Africa.

\section{AFRICA'S PUBLIC SERVICE DELIVERY AND PERFORMANCE REVIEW}

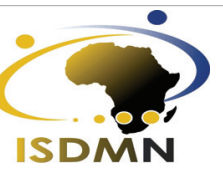

"Africa's Development Watch" 


\section{INTRODUCTION}

There is a growing concern that monitoring and evaluation should also be participatory in South Africa with more opportunities to promote development and accountability. The process of policy evaluation and monitoring can promote political and administrative accountability in the public sector. It can also be used to measure performance and efficiency, by evaluating whether the intended objectives are met/ achieved. Recently, different stake-holders are critically scrutinised the role of the state in service delivery, with some reservations on failure to include all participants in the Government Wide Monitoring and Evaluation (GWME) agenda. Some of the participants like the NGO's and some interest groups have long been tracking government performance on how public money is spent, but their involvement has been unofficial and out of the scope of GWME.

The desirable methods of participation include public forums, reviews, panel discussion, izimbizo, media and briefings, central information contact, survey polls, telephone hotlines, e-governance and survey and polls. This paper argues that public participation methods can be strategically integrated to make the GWME to be accepted nation-wide by a variety of stakeholders in South Africa using a number of theoretical and empirical evaluation criteria that are essential for effective participation. This paper suggest that the synergy in the practice of monitoring and evaluation at local level and public participation can assist in addressing gaps from resource allocation and service delivery in South Africa.

Trend setters in different countries made progress in implementing Participatory Monitoring and evaluation approaches, lessons have to be learnt to adopt the best practices that can offer innovative ideas for tracking service delivery and learn from change that is brought up by the participants. Literature reviewed imply that South Africa can learn different PM\&E approaches from other success cases in Brazil, Kenya, Canada, Zambia and Vietnam. The whole process needs a careful scrutinisation and rationalization of priorities for assessment, while the communities will indicate their dissatisfaction and demands.

This paper presents a literature reviewed on experiences in participatory monitoring and evaluation from global and regional perspectives, differing in the context and in potential use and methods of participation by various stakeholders. This paper attempts to make a contribution by addressing the paucity of literature in South Africa on how PM\&E can be cascaded to the civic organisations and local sphere of the government. The literature review is drawn from different sources; including articles from accredited journals, books, policy 
documents, academic papers, annotated bibliographies, manuals and guides and other overview papers on M\&E. After introducing the problem, the paper will be conceptualise $P M \& E$, review literature on the best practice of integrating participation in M\&E, the implications for development and accountability and conclusions and recommendations.

\section{Conceptualising the notion of Participatory Monitoring and Evaluation}

This section of the study explores the synergy between significant concepts in order to locate the contextual significance of PM\&E. The history of PM\&E revolve around the various participatory research traditions, including participatory action research (PAR) spearheaded by Paolo Freire (1972), Fals-Borda (1985) and ( Estrella \& Gaventa, 1997). The literature reviewed establishes no single definition, rather a broad scope conceptualizing PM\&E. The key area of understanding PM\&E is to conceptualise participation context of. However, it is important to locate participation in the SA Constitutional context. The Constitutional mandate was inherited from the Freedom Charter declaration of the inclusive approach in governance when asserting that 'the people shall govern' (Gumede, 2007: 29). South Africa's constitutional democracy is representative and participatory in nature. The representative aspect embraces multi-party and proportional representation. The regular elections based on a common voters'roll-party democracy, are achieved through regular elections every five years in that it guarantees involvement of each citizen in public life in between elections. To this extent, public participation is linked to the right of political representation. Similarly, public participation is a legislative mandate and part of democracy that has is still canvassed international as a right in public discourses.

Participation can be regarded as a tool and an approach for involving stake holders and actors in decision-making regarding issues affecting them. Theron $(2008,1003)$ locate participation in different discourses; such as putting people in the efforts of development in order to share in control and benefit over development initiatives and resources. Spaces for participation are created when governments are transforming or re-structuring their economies like in Brazil's Porto Alegre and in South Africa, affirming the marginalised and previously disadvantaged groups and during the inception of a democratic transformation. An inclusive approach of participation can recognise the rights of most of existing structures in the society to voluntarily participate towards decisionmaking, views and preferences. The process will be more effective if the knowledge and the experience of a range of stakeholders, including the poor and vulnerable groups; especially women are tapped, and their perspectives are 
systematically incorporated into the design and the implementation of the PM\&E.

Several governmental and non-governmental groups in South Africa have been actively involved in planning and prioritisation of resource allocation like in the form of public forums and IDPs, and less involved in monitoring and evaluation. Planning and evaluation are inextricable linked during project management. However, evaluation refers to the act of valuing the worth or effect of particular policies, programmes and projects. Evaluation provides credit worthy and value of what is evaluated. Policy evaluation is a careful assessment of public interventions and programmes, while monitoring seek to ensure that actual performance is in line with expected or planned targets for performance and gaps are addressed. Monitoring is a continuous process while evaluation can be done at the end of the intervention or implementation of the programme or projects.

The World Bank (2011) asserts that Participatory Monitoring and Evaluation (PM\&E) is an active engagement and judgment process through which stakeholders at different levels engage in monitoring and evaluation of an intervention or a programme. It concentrates on the active engagement that result to identification of a gap and suggest correction actions by primary stakeholders. Since the government representatives in a developmental state take a lead, correction plans are submitted to the umbrella body of the M\&E for advice, like the Presidency in the case of South Africa. According to the World Bank (2008) the core principles of PM\&E are based on the following assumptions:

- Primary stake-holders are active participants' not just sources of information,

- Building capacity of local people to analyse, reflect and take action,

- Joint learning of stake-holders at various levels, and

- Inductive commitment in taking corrective actions/ measures

However, the table below indicates the difference between the conventional monitoring and evaluation and the Participatory Monitoring and Evaluation. 


\begin{tabular}{|l|l|l|}
\hline \multicolumn{2}{|c|}{ Conventional M\&E } & \multicolumn{2}{c|}{ Participatory M\&E } \\
\hline $\begin{array}{l}\text { Who plans and manage } \\
\text { the process }\end{array}$ & $\begin{array}{l}\text { Senior managers } \\
\text { Or outside experts }\end{array}$ & $\begin{array}{l}\text { Local people, project } \\
\text { staff, managers, } \\
\text { stakeholders and } \\
\text { facilitators. }\end{array}$ \\
\hline $\begin{array}{l}\text { Role of primary stake- } \\
\text { holders (intended } \\
\text { beneficiaries). }\end{array}$ & Provide information only & $\begin{array}{l}\text { Design and adapt the } \\
\text { methodology, collect } \\
\text { and analyse data, share } \\
\text { findings and link them } \\
\text { to action. }\end{array}$ \\
\hline $\begin{array}{l}\text { How success is } \\
\text { measured. }\end{array}$ & $\begin{array}{l}\text { Externally defined, } \\
\text { mainly quantitative } \\
\text { indicators. }\end{array}$ & $\begin{array}{l}\text { Internally-defined } \\
\text { indicators, including } \\
\text { more qualitative } \\
\text { judgment. }\end{array}$ \\
\hline Approach & Predetermined & Adaptive \\
\hline
\end{tabular}

Table 1: difference between conventional monitoring and evaluation and the Participatory Monitoring and Evaluation (Source: The World Bank. http://go.worldbank.org)

Conventional approach to M\&E offers new innovative ways of assessing and learning from change. It has involves experts like consultants from outside in order to measure performance against pre-set indicators, using the standards procedures and tools. However, PM\&E differs from more conventional approaches in that it seeks to engage key project stake-holders more actively in reflecting and assessing the progress of their project and in particular the achievement of results.

The primary problem of this study is the fact that implementation of the GWME in South Africa has excluded local communities/ stakeholders in participating in the main stream of the GWME agenda. Similarly, the pro-active structures in South African M\&E include the Presidency, the office of the Auditor General, the Public Service Commission, the National Treasury, Department of Performance Monitoring and Evaluation, The Parliament and legislatures, International Development Evaluation Association, African Evaluation 
Association and NGP's such as IDASA and municipalities. However, the presidential hotline allows the communities to directly report their challenges in service delivery and wait for the responses. However, PM\&E requires communities to by not only tracking the service delivery by public agencies, but to further build capacity of local people to analyse, reflect and take action. This paper argues that the GWME should cascade in to lower levels of the communities and grass-roots interest and action groups using the principles of PM\&E.

\section{LITERATURE REVIEW}

\section{Integrating participation into monitoring and evaluation}

Different scholars allude on the integration of participation elements in monitoring and evaluation coordinated by various stakeholders such as NGO's, donors, research institutions, government, civic organisations and communities. They contest different applications for different purposes using tools such as participatory learning methodologies, capacity development, participatory action research, theory driven effective evaluation as well as other conventional evaluative approaches.

The notion of a participatory approach in evaluation can offer some benefits in goal setting and goal achievement. According to Scarinci (2009: 221) planning and implementation of participatory evaluation strategy is guided by the principle of participatory research, which is represented by community partners, community based organisations, community leaders and agents of change such as ministers, teachers, politicians etc. Wallace (2008: 201-2017) alludes on various evaluation models; such as the Theory-based evaluation, Participatory evaluation and Growth mixture evaluation.

The multi-component of the methodology for collecting data requires a triangulated mixed-method evaluation plan focusing on process, impact and outcomes using both qualitative and quantitative assessments. The information allows the panels to detect the impact of government programmes to the target groups. It also allows alternatives to be developed and implemented. At the centre of the debates for evaluation are the resources; such as information, knowledge and time. Information allows the panel to detect the impact of government programmes to the target groups. It also allows alternatives to be developed and implemented. When impact evaluation has revealed that programme intervention effects were inconsistence with project goals and objectives, network steering committee members were alerted to the need to 
either change the existing intervention strategies, or create different strategies altogether. The outcomes evaluation focused on assessment of the extent to which programme goals and objectives were reached. The logic model guided the process, impact and outcomes evaluation. This model links program inputs and activities to program outcomes and ultimately to the main goals of the project.

Wallace (2008: 201) affirms that evaluation models can be a mixture of implicit and explicit theory and theoretical assumptions. The theory based evaluation models prescribes using theory derived, either from practical experience or empirical research, to articulate causal linkages between activities implemented and the short and long term outcome. In all aspects of evaluation, stakeholders participation in the process of developing theory-based model of causal mechanisms and intervention effects. Growth mixture modelling is generally a latent variable growth modelling technique, uses longitudinal data to create trajectories of individual program participate growth (Muthon \& Khoo, 1998).

Citizen participation is crucial at the planning, and evaluation phase of public programmes and projects. This offers a direct engagement on assessing whether the set planned goals and objectives are achieved, and this can later offer some insights on the costs and the benefits of the programme or project. Ille \& others (2012: 59) argue that the voices and the views of the stakeholders require an approach that is consultative, cooperative and committed to consensus building. The essence of such participation should not be just to meet other policy demand but to suggest correction plan. Any misgivings are thoroughly engaged, discussed and are guided by the principle of inclusiveness. Stake-holders, beneficiaries of the programmes need to be aware of the circumstances affecting the project/ programme while it is implemented and after the implementation. Performing institutions and experts need to constantly monitor the progress during the implementation to minimise the risks by providing appropriate feedback to stakeholders and beneficiaries.

There is a growing interest in M\&E in municipal planning. Municipal officials and governors are following the footsteps of their trend-setters in monitoring and evaluation. The principle of monitoring and evaluation has been practiced since the rational comprehensive model became dominant in urban planning. The emerged literature considers the nature and roles of M\&E in the context of strategic planning (Nutt, 1992; Seasons, 2008). While urban planners monitor and evaluate municipal projects using technical tools and techniques, community organisations and civic associations are excluded from the process. This implies the under-use of PM\&E in municipal planning. This paper argues 
that participatory monitoring and evaluation can respond to the disjuncture in the planning theory and the practice of monitoring and evaluation in local government.

Parkison's $(2009,229)$ assertion of PM\&E is on the alignment of politics and evaluation. His contestation of evaluation of programme is summoned by the existence of power and perceptions; where stakeholders hold and exercise power through pockets of political decision-making that varies with intensity of their choices and benchmarks. Weiss's (1973) and Hamburger's (1991) comparison of evaluative practices and context in developing countries, contrasted with the North American experience, argued that the recognition of the role of politics and of the need to involve stakeholders in evaluation was still quite limited in developing countries. Evaluation designs were mainly dominated by the needs and the interests of the foreign donors like the World Bank and UNDP and the programme beneficiaries as a feedback mechanism and a tool for monitoring and assessing accountability after development programmes are implemented. The pragmatic stand for the Participatory Monitoring and Evaluation has been practiced in the global North and it has been canvassed by scholars with focus on social justice and the empowerment of the marginalised, and its roots in practice and theory founded from the global South (Parkinson, 2009: 230).

Participatory monitoring and evaluation differs from the conventional monitoring and evaluation in the sense that MP\&E attempts to bring on board all the stakeholders in all aspects of the process. PM\&E gained popularity in recent years in the sense that it recognises that stakeholders should not only be involved in defining the problem but also in collecting, analysing and interpreting data for project development and evaluation. Holte-Mckenzie, et al (2006) offers some insights on the process of developing a participatory monitoring and evaluation strategy for Kenyan youth-based NGO. The lessons that emerged from the study implicated the imperative of prioritisation for monitoring and evaluation using the NGO to carry out effective PM\&E, with potential youth engaging researchers with communities and participants.

The analysis of using potential NGO as a participant is to engage in a learning process where the youth can acquire skills such as life skills, defined self-esteem, confidence, team-work and decision-making while conducting the PM\&E. The ultimate goal of developing capacity and training during the PM\&E should be to build upon PM\&E as a learning tool to enhance their capabilities. The learning process/ capacity development is about the people, their organisations and institutions, taking charge of the process in recognisance of their values, beliefs, 
and provide some expertise, opinions, inputs during the intervention and after the intervention.

The other trend in the practice of PM\&E while building capacity can be enhanced through Participatory Action Research (PAR), where an agency is contracted to design, implement the intervention and evaluate a social programme. In such cases, participatory elements are integrated into the evaluation design, so that stakeholders can provide practical knowledge to guide study decision-making. Wallace $(2008,2010)$ supports this type of evaluations, and makes some suggestions in adopting a type of a Participatory, Theory-driven Effectiveness Evaluation (PTBEE), where the design of a programme is based on implicit or explicit theory-based evaluation. The limitation of effective evaluations is the fact that it is not designed to be collaborative, while it hinges about decisions about outcomes to be measured, how to measure them and when the outcomes and by who is appropriate to be in the comparison groups for measuring the outcomes. This type of evaluation requires experts to answer those decision more than any one.

\section{THE INCLUSION OF PARTICIPATION INTO THE GWM\& E IN SOUTH AFRICA}

\section{The government wide monitoring and evaluation in South Africa}

Monitoring and evaluation in South Africa was introduced in 1994, prior to that the pre-condition of M\&E did not exist. Initially, the evaluation of public programmes was donor driven with many expectations from the agenda of the donor on whom and how should evaluation be done. Public Service Commission (PSC) mandated the practice of M\&E of programmes, with public standards through the Batho Pele Principles and public service culture. In 2005, GWM\&E was launched and centralised within the Presidency.

Monitoring and evaluation is envisaged to improve public participation, as state performance through open dialogue and public scrutiny. The Presidency is driving the process of ME- its sets framework for M\&E in SA, drawn on existing transversal systems such as the Treasury (value for money), Public service Commission (governance), and DPSA (service delivery). In this sense the public service is being transformed to service people better. The GWM\&E system in South Africa is intended to facilitate a clear sequence of events based on the critical reflection and managerial actions in response to analysis of the relationships between the deployment of inputs, the generation of service delivery outputs, their associated out comes and impacts. 
Govender and Penceliah (2012: 7)) assert that M\&E systems are needed to manage performance and application of result based M\&E that is included in programme, project and policy; local, provincial and national levels; knowledge capital; and transparency and accountability. The GWM\&E system is intended to facilitate a clear sequence of events based on critical reflection and managerial action in response to analysis of the relationships between the deployment of inputs, the generation of service delivery outputs, their associated outcomes and impacts (GWM\&E Report). Ille et.al. (2012; 15) assert that the GWM\&E system produces the following outputs:

- Improved quality of performance information and analysis at programme level within departments and municipalities.

- Improved monitoring and evaluation outcomes and impact across the whole of government through, eg Government Programme of Action bimonthly Report, Annual Country Progress Report based on the national indicator etc.

- Sectoral and thematic evaluation reports.

- Improved monitoring and evaluation provincial outcomes and impact in relation to Provincial Growth and Development Plans.

Levin (2005) argues that some of the current challenges facing government in implementing the GWM\&E include: coordinating of cross cutting programmes/ projects, to ensure that everyone is working towards a common goal, inability to determine the impact/ success of current programmes/ projects, insufficient learning and lack, lack of pro-active and focused intervention,

Similarly, the integration of participation into M\&E would bring better results where plans and agreements would be signed by key partners in each identified objectives. The idea would be to isolate the limitation of the conventional M\& $E$ and manage the process in a collaborative and consultative manner.

\section{PROSPECTS OF PM\&E IN SOUTH AFRICA}

\section{Problem solving}

Participatory monitoring and evaluation can provide logical in its application for problem solving by assessing successes and failures of public programmes and projects. It involves a systematic research process where the community is the 
object of the study. One of the common functions of PM\&E is to evaluate the impact of a given programme and changes that have occurred as a result of programme initiative. ljeoma,(2011: 1298) asserts that approaches for problem solving can include intuitive, judgmental and analytical. The PM\&E approach is applicable different than the conventional evaluation in the sense that community is seen as part of the problem, and some community members are also involved in addressing or solving the problem. A lesson can be learnt from the case of the Siavonga Agricultural Development Project (SADP) in Zambia, where PM\&E was designed mainly for the purpose of improving project management through diagnosis approach (Nagel, et al, 1992).

\section{Capacity development}

During the process of implementing PM\&E projects, participants experience skill transfer and empowerment in the issues affecting them and their communities. Socorinci.et.al. $(2009,222)$ asserts that community empowerment approach holds that, before community members must first be organized and empowered with knowledge relevant to the projects before they participate in the design and implementation of projects. Project success depends on their understanding of issues and participation in the PM\&E process. In return, PM\&E can assist the government officials to identify how projects and programmes impact on beneficiaries with the intention to reorient public policy. The participatory impact study of soil and water conservation programme implemented in Kenya illustrate how PM\&E can contribute to capacity building (Thompson \& Pretty, 1995). Similarly, this impact study was good in revealing local farmers perspectives and criteria for assessing project impact, findings can be used to help improve the Ministry of Agriculture's operational policies and procedures.

\section{Social accountability}

PM\&E can provide a platform for social accountability of local and national government programmes to communities. There is a process of collective agreement among the members of the panels conducting evaluation. According to Cloete and Thornhill (2012: 277) accountability imply that the responsible officials are responsible for ensuring that they give account for any act that is prejudicial to the interest of the community. In exercising this responsibility, the legislatures put a stop to high-handed bureaucratic action. However, the merits for accountability are life-long in the sense that they can promote selfdevelopment in communities and civic organizations. It is critical that the 
evaluation is jointly designed by the panel members. In the context of a developmental state; the GWM\&E representative would have more influence on the evaluation than others. In reference to other country's case, the Cooperative for American Relief Everywhere (CARE) in Zambia established a PM\&E process which aims at building organisational capacities - and later enhanced social accountability through stakeholders' participation (Estrella \& Gaventa).

\section{Participation}

The involvement of the community on participation panels can guarantee legitimacy of the results by community members. The participants on PM\&E can also create network where drivers are change agents and experts. While the process can be rewarding, it can also be challenging- participant panels can also be used as sources of conflict where members contest space for participation. Dominant groups from the communities and civil society groups can abuse power when in the process of negotiating for better decisions. This might lead to unequal participation and delay of the process of evaluation.

Theron (2008: 9) asserts that it is imperative to understand the role and the complex relationship between the change agents and the communities in the context of participatory development. Change agents are often regarded as outsiders while community members are regarded as insiders representing community needs. Ideally, public programmes would be designed to benefit the target groups by providing an environment for social learning process, extracting empowerment approach, a top-down and bottom-up approach and achieve results/ outcomes.

The presence of change agents and experts in participatory monitoring and evaluation of programmes can offer some insights on both the PAR and participatory development. The achieved outcomes can also assist in testing theories and making a contribution to the existing knowledge about participatory programme evaluation and understanding of community development. Change agents and experts can also establish a linkage between programme objectives and achieved outcomes in a logical way. They can evaluate causal linkage between outputs and purpose. This concerns the causal linkage between outputs and purpose. For example, if the health clinics are built and the patients are given medication and well cared, health standards and conditions will be improved for communities. 


\section{Resource and information}

Similarly, information is an important resource that should be properly handled. Programme planning should encompass the identification of proper information to be used during programme evaluation. Responsibilities on coordination and management of information rely on experts' abilities and capabilities of work. The success of discussions by participants depends on the availability of information prior engagement. Programme evaluation involve many tasks such as planning and design, assembling of programme evaluators/panels, data collection, registration, data analysis and issuing of the reports.

Participatory monitoring and evaluation is effective when developed and implemented using a broad-participation approach of primary and secondary stake holders. They encompass many roles and responsibilities which require high levels of commitment that only a buy-in on the part of stakeholders can serve as a guarantee on their part. Primary responsibility of stakeholders in M \&E include; attending meetings, contributing on time and money, providing information/ opinions in a survey, commitment on achieving objectives and debating, negotiation and debating during panel discussions.

\section{Organisational strengthening}

Although M\&E is centralised in the Presidency, there is a need of organisational requirements that include management skills such as cost accounting and budgeting, human resources management, research skills. The implementation of PM\&E in South Africa implies greater improvement in government performance especially in programme and project management. One of the significant merits of PM\&E is the enhancement of sustainability, repplicability, and effectiveness of development efforts through the strengthening of people's organisational capacity. Holte-Mckenzie, et al (2006: 365) asserts that the designing and implementation of the Moving the Goalposts Kilifi (MTGK) in Kenya focused on teaching and promotion of girls in football- to foster their life skills- defined as self-esteem, confidence, teamwork and capacity building. Lessons can be learnt in the development and implementation of this evaluation strategy for Kenya youth-based NGO, illustrate the success of PM\&E in participation, capacity building and impact assessment. 


\section{IMPLICATIONS FOR GOOD GOVERNANCE IN SOUTH AFRICA}

The exploration of Participatory monitoring and evaluation imply some improvement in the praxis of good governance in South Africa. The participatory landscape in South Africa emerged as a reflection of both radical and political discourse in developing the nation, and as part of good governance. Participatory monitoring and evaluation fits well in the rhetoric of good governance. Sharon Panderis (2012:4) posits that features of good governance include sound financial regulation, institutional reform, transparency and an active role of participants in decision-making. Good governance impels a manner of exercising power in the management of resources for sustainable development. Its embrace elements of participatory, responsive, transparent, responsive, accountable, effective, equitable and promotes rule of law (UNDP, in IDLO, 2003). In the context of the study, PM\&E can establish an environment where public officials and political office bearers and other stakeholders can share space in engaging on planning and evaluating of how economic resources are allocated. They can also identify gaps and suggest strategies and approached to address the problem.

Participatory monitoring and evaluation can assist in improving governance in South African public service by coordinating performance of public programmes through the provision of consolidated and aggregated reports from performing agencies/departments on monthly basis. Even though it would be difficult to manage stake holders, PM\&E can assist with the creation of common goals through the linking of departments/sectoral structures activities with the panel used for evaluation. It is critical that the panels are linked to performing institutions to promote a culture of learning by making the information ready and available and promote a culture of feedback. Information can also be provided in order to promote a proactive intervention and participation while preserving limited resources.

However, there are credible results in the GWM\&E practices on the governance scorecard. Reports of the Auditor General improve accountability in government departments and local municipality in South Africa. There is improvement also in citizen's perceptions of performance on the Presidential anti-corruption hot-line. Over the years, the Public Service Commission (PSC) has a key role in promoting M\&E system in service in the country and beyond our borders. There is a case in point - in the creation of the PSC Transversal M\&E System which has been operational since 2001.

New participatory institutional landscapes have emerged as a reflection of more radical and politicised participatory discourse and as part of the 'good' 
governance agenda and neo-institutional perspective. The notion of participation fits very well into the ambit of the new rhetoric surrounding good governance, institution building and capability expansion. Careful assessment on power relations and how space is shared among the stakeholders is imperative for the promotion of good governance. Power games and politics can stifle the progress of $P M \& E$.

\section{CONCLUSIONS AND RECOMMENDATIONS}

This paper canvassed for a participatory monitoring and evaluation that is inclusive of all stake holders. Participation in monitoring and evaluation can be costly in the sense that it require the use of resources like information, time, finances, skills and expertise, leadership and management. However, the ability and capacity of these resources can also imply trade-offs among the participants. The premise of this article is to canvass for the PM\&E using different lenses that supports an inclusionary approach of different stakeholders. The case of the practice of Monitoring and Evaluation in government departments and agencies doesn't amount to stake-holders participation in a democratic country like South Africa, where public participation is broadly supported. Country cases support the notion that participation can be integrated to $M \& E$ in different approaches; like project management and local planning, participatory development, capacity development and learning, resources and information sharing and strengthened infrastructure and organisational requirements.

The main recommendation for the success of the PM\&E is to provide training and information of participants before the evaluation process by experts and government officials. The success of the process depends on understanding the interests of different stake holders. Similarly, lack of skills in some stake-holders can be a limitation in participation- and that can lead to partial or no fulfilment in achieving the desired outcomes of conducting monitoring and evaluation. Findings from the literature indicate merits on the prospects in PM\&E in South Africa. 


\section{List of References}

- Brunner, R.D. Context-sensitive monitoring and evaluation for the World Bank. 2004. Policy Sciences 37: 103-136.

- Cameron, R. 1999. Democratisation of South African Local Government. Pretoria: Van Schaik publishers.

- Cloete, F. \& de Coning, C. 2012. Improving Public Policy. Pretoria: Van Schaik.

- Estrella \& Gaventa. Who counts reality? Participatory monitoring and evaluation: A literature review. IDS Working Paper 70. The World Bank.

- Fan, Q. An evaluation Analysis of E-government Development by Local Authorities in Australia. International Journal of Public Administration, 34(10) 926934.

- Govender, I, J. 2011. The role of monitoring and evaluation systems for service delivery in Local Government. Administration Publica. 19. (4).

- Gumede. M.W. 2007. Thabo Mbeki and the battle for his soul of the ANC. Cape Town: Hirt \& Carter.

- Holte-McKenzie, M. Forde, S. \& Theobald, S. Development of participatory and monitoring strategy. 2006. Evaluation and Programme Planning .29. pp. 365- 376.

- lyer-Raniga \& Treloar, g. A Context for Participation in Sustainable Development. Environment Management Vol. 26, No. 4, pp. 349-361.

- ljeoma, E.O.C. Structural provisions for establishing and managing monitoring and evaluation units in government units. 2011. Journal of Public Administration. 46 (4).

- Ille, IU. Eresia-Eke, C., and Allen-Ille, C. Monitoring and evaluation of projects, programmes and projects. 2012. Pretoria: Van Schaik Publishers.

- Kuzman, A. 2012 Participatory training evaluation method (PATEM) as a collaborative evaluation capacity building strategy. Evaluation and Programme Planning. 35.pp. 543-546.

- Marisol, E \& Gaventa, J. 2010. Who counts reality? Participatory monitoring and evaluation: A literature Review. IDS working paper 70. 
- Matsiliza. N.S. 2012. Participatory Budgeting for sustainable local governance in South Africa. Journal of Public Administration. 47. (2).

- Nagel \& Uwe. 1992. Developing a participatory extension approach: A design for the Siavonga District, Zambia. Berlin Technical University, Center for advance Training in Agricultural Development.

- Parkinson, S. 2009. Power and perceptions in participatory monitoring and evaluation. Evaluation and programme planning 32. p. 228-237.

- Seasons, M. 2003. Monitoring and Evaluation Planning Association. Journal of American Planning Association. Autumn. 2003. Vol.69, No.4.

- Sharon Penderis. 2012. Theorizing Participation: From tyranny to emancipation. The Journal of African \& Asian Local Government Studies. Vol.1. (3).

- Theron, F. 2008. The development change-agent: a micro level approach to development. Pretoria: Van Schaik publishers.

- Thomson \& Pretty. 1995. Sustainable indicators for soil conservation. A participatory impact study and self-evaluation of the Catchment approach of the ministry of Agriculture, Kenya. A paper submitted in the Journal of Soil and water conservation.

- Van Donk, M. Swiling, M. Pieterse, E. Parnell, S. 2008. Consolidating Local Government: Lessons from the South African experience. Cape Town: UCT Press.

- Venter, A. van der Waldt, C. Phutiagae, K. Khalo, T. van Niekerk, D \& Nealer, E. 2007. Municipal Management: serving the people. Cape Town: Juta \& Co.

- Wallace, L.T. 2008. Integrating participatory elements into effectiveness evaluation. Studies in Education Evaluation 34 . pp. 201-207.

\section{AUTHOR'S CONTACT:}

\section{N.S. Matsiliza}

Department of Public Management,

Tshwane University of Technology

Email: matsit@webmail.co.za 